\title{
EDITORIAL
}

\section{Nueva plataforma editorial: un paso más}

\author{
Luis Salar
}

Director de FARMACÉUTICOS COMUNITARIOS.

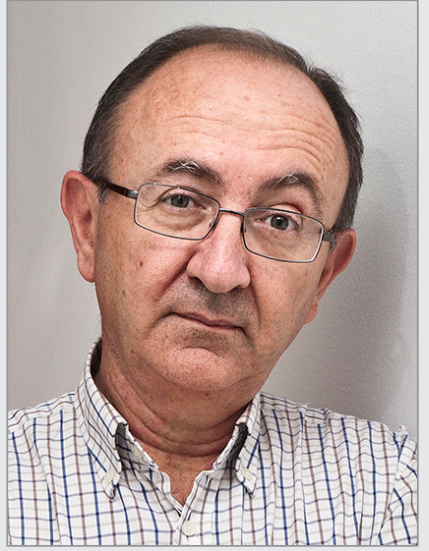

Luis Salar

PALABRAS CLAVE

Publicación, indexación

\section{KEYWORDS}

Publishing, indexing
La investigación científica es uno de los principales motores de desarrollo de la humanidad, si no el más importante. Se promueve preferentemente desde grandes institutos públicos o privados y en las universidades, y una parte fundamental de su proceso es la publicación de los resultados en revistas científicas. Hay miles de estas revistas, dedicadas cada una a su especialidad. Para poder encontrar lo publicado sobre algún tema de interés se acude a las búsquedas en las bases de datos que "indexan" las principales revistas. Hay muchas de estas bases de datos y todas útiles, pero en biomedicina la base de datos por excelencia es Medline, o su plataforma en internet PubMed.

La investigación de calidad no se hace solo en los grandes centros, también en otras entidades más pequeñas como puede ser el caso de las farmacias comunitarias. Nosotros, como farmacéuticos comunitarios, no contamos generalmente con grandes medios. Tampoco somos profesionales de la investigación dedicados a ella a tiempo completo. Contamos con menos medios y tenemos que dedicar la mayor parte de nuestro tiempo a nuestro trabajo profesional diario. Sin embargo, alli donde se encuentre un profesional con curiosidad suficiente puede desarrollarse la investigación.

Un problema añadido a la investigación en farmacia comunitaria es la publicación de sus resultados. Hay pocas revistas dedicadas a ello.

Farmacéuticos Comunitarios nació en 2006 con ese objetivo, y más aun en su segunda época bajo la dirección de Floro Andrés, su anterior director. El objetivo de esta revista es dar a conocer la investigación realizada en farmacia comunitaria y, también, facilitar la publicación de trabajos de jóvenes investigadores contribuyendo así a mejorar su currículum. Pero para alcanzar estos objetivos es necesario que esta revista aparezca en las principales bases de datos de indexación de revistas. Ya estamos en muchas de ellas, basta con mirar el apartado "indexación" en nuestra web. Pero nos falta la principal: Medline.

Uno de los requisitos imprescindibles para aparecer en Medline es contar con una plataforma para la gestión online de los manuscritos. Esa plataforma se inaugura con la publicación de este número. A partir de ahora los autores ya no enviarán sus manuscritos por correo electrónico como se venía haciendo. Deberán hacerlo por esta plataforma, debidamente señalizada en la web, y toda la comunicación necesaria durante el proceso de edición será también a través de esta plataforma.

Para el lector los cambios serán imperceptibles. Para el autor creemos que supondrán una mejora en la calidad y trasparencia de todo el proceso.

Sin duda, esto es un paso más en el proceso de mejora continua que Farmacéuticos Comunitarios lleva dando desde hace años y con el que esperamos reforzar mucho más el valor de nuestra revista como canal de difusión de toda la investigación de calidad que se hace en el campo de la farmacia comunitaria. 